Интернет-журнал «Науковедение» ISSN 2223-5167 http://naukovedenie.ru/

Выпуск 6 (25) 2014 ноябрь - декабрь http://naukovedenie.ru/index.php?p=issue-6-14

URL статьи: http://naukovedenie.ru/PDF/45PVN614.pdf

DOI: 10.15862/45PVN614 (http://dx.doi.org/10.15862/45PVN614)

УДК 378

Бичева Ирина Борисовна

ФГБОУ ВПО «Нижегородский государственный педагогический университет им. К.Минина»

Россия, Нижний Новгород Доцент кафедры инновационных технологий менеджмента

Кандидат педагогических наук, доцент

E-Mail: irinabicheva@bk.ru

Китов Анатолий Григорьевич

ФГБОУ ВПО «Нижегородский государственный педагогический университет им. К.Минина»

Россия, Нижний Новгород Заведующий кафедрой технологии транспортных процессов и систем

Кандидат технических наук, доцент

E-Mail: anatolykitov@yndex.ru

\author{
О готовности преподавателей \\ к инновационным преобразованиям \\ В учебно-профессиональной деятельности
}


Аннотация. Инновации занимают особое место в системе образования, как социального института и готовность преподавателей к инновационным преобразованиям является важным условием модернизации образования. От готовности преподавателей принять и реализовать инновации во многом зависит качество предоставляемых образовательных услуг и, как следствие, результат образования. Однако, в научной литературе недостаточно исследований, подтверждающих необходимость формирования готовности преподавателей к инновационным преобразованиям в учебно-профессиональной деятельности.

В данной статье раскрыты научно-теоретические аспекты и ведущие тенденции в развитии инновационных процессов в системе образования, выделены принципы инновационного учебного процесса, рассмотрены интегративные качества, составляющие сущностные черты личности инновационного типа.

Готовность человека к эффективной деятельности рассматривается в теории и практике образования как условие успешного выполнения деятельности, как избирательная активность, как отношение личности к себе (как активному субъекту образовательного процесса), как комплекс способностей, включающих в структуру различные свойства и качества личности.

В публикации говорится о том, что быть готовым к инновационной деятельности значит, обладать качествами и способностями, обеспечивающими организацию образовательного процесса в режиме развития. Готовность преподавателей к инновационным преобразованиям в учебно-профессиональной деятельности рассматривается в качестве необходимой составляющей личностно-профессионального развития, обеспечивающего формирование новых нравственно-гуманистических позиций, качеств, непрерывность роста профессиональной образованности.

В статье дано описание компонентов готовности преподавателей к инновационным преобразованиям, включающие мотивационно-ценностные установки, профессиональную компетентность, личностную и технологическую готовность, а также критерии готовности преподавателей к инновационной образовательной деятельности.

Ключевые слова: инновация; инновационный процесс; принципы инновационного учебного процесса; инновационный тип личности; готовность; готовность к инновационной деятельности; критерии; компоненты готовности к инновационным преобразованиям.

\section{Ссылка для цитирования этой статьи:}

Бичева И.Б. Китов А.Г. О готовности преподавателей к инновационным преобразованиям в учебнопрофессиональной деятельности // Интернет-журнал «НАУКОВЕДЕНИЕ» 2014. № 6 http://naukovedenie.ru/PDF/45PVN614.pdf (доступ свободный). Загл. с экрана. Яз. рус., англ. DOI: 10.15862/45PVN614 
В современных условиях модернизации образования перед педагогическим сообществом актуализируются новые целевые ориентиры осуществления профессиональной деятельности в поиске нового содержания образования, инновационных технологий обучения, на базе которых может быть сформировано концептуальное мышление обучающихся и осуществлен выбор концептуальных оснований их будущей профессиональной деятельности, возможность для обучающихся учиться, делая, решая проблемы, критически анализируя разнообразные точки зрения.

Понятие «инновация» (лат. in - в, novus - новый) трактуется как нововведение. Н.И. Лапин отмечает, что уже этимология слова «нововведение» (innovation) указывает на то, что оно означает «введение», т.е. процесс создания и использования новшества [10].

Рассматривая нововведения, как один из важнейших факторов развития современного мира, Н.И. Лапин, А.И. Пригожин, Б.В. Сазонов, В.С. Толстой связывают степень успешности развития людей, организаций и обществ со способностью к продуцированию и восприятию разного рода нововведений. Они рассматривают нововведение как процесс, сущность которого составляет инновационная деятельность [11].

В качестве объектов инноваций в системе образования чаще всего рассматриваются цели, формы организации и структура образовательного процесса, технологии обучения, субъектное взаимодействие, др. С точки зрения принадлежности к той или иной части учебновоспитательного процесса, выделяют следующие группы (или типы) нововведений:

- $\quad$ в содержании образования;

- $\quad$ в методиках, технологиях, методах учебно-воспитательного процесса;

- $\quad$ в организации учебно-воспитательного процесса;

- $\quad$ в управляющей системе общеобразовательного учреждения.

Представляют интерес исследования Г.И. Герасимова, Ф.Ю. Дудкина, Л.В. Илюхиной, А. Инкелес, Д.А. Карповой, М. Крозье и др., в которых рассматриваются качества личности, предопределяющие возможности инновационного взаимодействия различных субъектов инновации: инновационный тип личности, инновационная школа как коллективный субъект, профессионально-педагогическое сообщество как субъект инновации.

Например, в аналитической модели современной личности Д.А. Карповой значимыми чертами личности инновационного типа определены: [8, с.93-94].

1. Открытость экспериментам, инновациям, изменениям.

2. Готовность к плюрализму мнений, признание существования разных точек зрения без опасения изменения собственного видения мира.

3. Ориентация на настоящее и будущее, а не на прошлое.

4. Уверенность и способность в преодолении создаваемых жизнью препятствий.

5. Планирование будущих действий для достижения целей, как в общественной, так и в личной жизни.

6. Вера в возможность регулирования и прогнозирования социальной жизни.

7. Чувство справедливости, основанное на уверенности в зависимости вознаграждения от вклада и мастерства.

8. Высокая ценность образования и обучения.

9. Уважение достоинства других вне зависимости от статусной позиции. 
Французский социолог М. Крозье, описывая типологические черты инновационной личности, отмечает, что способность людей к инициативе становится в современных условиях более значимым фактором развития, нежели оперирование материальными ресурсами, поэтому конкурентная борьба сосредотачивается не вокруг проблемы обладания материальными ресурсами, а за способность к быстрому обновлению, способность к нововведению. Среди ведущих качеств личности работника, наряду с компетентностью, знанием дела, столь же значимыми становятся инициативность, готовность к инновационным изменениям. А мобилизация этих качеств напрямую зависит от готовности и способности учиться [9].

В теории менеджмента особое внимание уделяется выделению критериев, необходимых руководителям для осуществления инновационного менеджмента, прежде всего, высокий уровень общественного интеллекта, наличие креативности - творческого, нестандартного подхода к делу, эмоциональная устойчивость, высокая мотивация достижений, ориентация на будущее; индивидуализм. [6].

Исследуя сущность и социальные механизмы инновации в образовании, $\quad$ Герасимов Г.И. и Л.В. Илюхина отмечают, что инновация выступает как особым образом организованная деятельность, самовоспроизводящая себя, поэтому она востребует совершенно определённую совокупность характерологических черт личности, среди которых авторы выделяют [3].:

- потребность в переменах, умение уйти от власти традиций, определяя точки развития и адекватные им социальные механизмы;

- наличие творческости как личностного качества и творческого (креативного) мышления;

- способность находить идеи и использовать возможности их оптимальной реализации;

- системный, прогностический подход к отбору и организации нововведений;

- способность ориентироваться в состоянии неопределённости и определять допустимую степень риска;

• $\quad$ готовность к преодолению постоянно возникающих препятствий;

- развитая способность к рефлексии, самоанализу.

На основе анализа теории и практики работы инновационных коллективов и инноваторов в области образования, ими выделены критериальные параметры типологии инновационности как качества профессионально-педагогической культуры:

• принята ли инновация как личностно значимая ценность;

- $\quad$ разделяется ли подход к инновации как к необходимому социальному механизму развития системы образования;

- $\quad$ понимается ли инновация в качестве целостной системы отношений и специфически организованной деятельности;

- переведено ли это отношение в организацию собственной профессиональной деятельности;

- $\quad$ в какой мере в собственной деятельности присвоена специфика инновационной её организации.

С учетом выделенных критериальных параметров типологии инновационности авторами обозначены следующие типологические группы: 
1. Инноватор - инновация принята как личностная ценность и присвоена как качество образа жизни - инновационность: инновация, понимаемая в качестве целостной системы, сознательно используется как механизм развития, опирающийся на специально организованную, продуктивную деятельность; полностью реализуется инновационная способность субъекта; сформирована и проявляет себя как качество профессионально - педагогической культуры инновационная деятельность.

2. Инновационно - ориентированный: инновация принята как личностно значимая ценность и рассматривается в качестве механизма развития системы образования; значительная часть инновационных процессов организуется на уровне нововведений, ещё не полностью реализуется представление об инновации как о целостной системе; инновационная способность субъекта используется, преимущественно в форме репродуктивной деятельности; сформировано и проявляет себя как качество профессионально-педагогической культуры инновационное поведение;

3. Индифферентный: профессионально значимой ценностью выступает необходимость обновления; представление о механизме развития сформировано преимущественно на уровне снятия «передового педагогического опыта»; новшества и нововведения используются по необходимости, в зависимости от степени и формы стимуляции; инновационная способность проявляется спорадически; сформирована и проявляет себя как качество профессионально-педагогической культуры неопределённость поведения.

4. Консервативно-охранительный: профессионально значимой ценностью выступает стабильность, упорядоченность; инновация не принимается как способ и средство развития; профессиональная работа организуется на основе усвоенного опыта предшествующих поколений с ориентацией на требование руководства; новшество осваивается в форме «внедрения»; инновационная способность не проявлена; сформировано и проявляет себя как качество профессионально - педагогической культуры консервативно-охранительное поведение.

Понятие «инновация» тесно связано с понятием «инновационный процесс». Инновационный процесс заключается в формировании и развитии содержания и организации нового. Он представляет собой совокупность процедур и средств, с помощью которых научное открытие или идея превращаются в социальное, в том числе, образовательное нововведение. Инновационный процесс можно рассматривать как процесс доведения научной идеи до стадии практического использования и реализация связанных с этим изменений в социальнопедагогической среде. В общем виде схема инновационного процесса может быть представлена следующим образом.

Первый компонент инновационного процесса - новации (новые идеи, знания) - это результат законченных научных исследований (фундаментальных и прикладных), опытноконструкторских и иных научно-технических разработок.

Вторым компонентом инновационного процесса является внедрение, введение новации в практическую деятельность, т.е. нововведение или инновация.

Третьим компонентом инновационного процесса является диффузия инноваций, под которой подразумевается распространение уже однажды освоенной, реализованной инновации, т.е. применение инновационных продуктов, услуг или технологий в новых местах и условиях [4].

Организация учебного процесса - основная учебно-профессиональная деятельность преподавателя, поэтому все инновации должны отражаться и формироваться в процессах подготовки и обучения студентов и могут быть направлены на изменение технологии, содержания обучения, форм работы с целью формирования профессиональной компетентности, образованности обучающихся. Построение инновационного учебного процесса обусловлено следующими принципами: 
- $\quad$ принципом ценностной ориентации (формирование профессиональной позиции);

- принципом гибкости (адаптивности), (оперативное реагирование на потребности, вызовы, изменения профессиональной среды, учет требований работодателей, что повышает конкурентоспособность будущих выпускников);

- принципом осознанной перспективы (понимание и осознание ближайших и будущих перспектив);

- п принципом интенсификации обучения (управление самостоятельной работой студентов с целью повышения активности и формирования потребности к непрерывному обучению в течение всей жизни);

- принципом модульности, в соответствии с которым содержание обучения представлено в виде модулей, каждый из которых включает требования к результату, содержанию, технологии обучения, организации самостоятельной работы, формам контроля.

Деятельность, обеспечивающая превращение идей в нововведение и формирующая систему управления этим процессом, является инновационной. Инновационная деятельность преподавателя становится источником новых идей для обучающихся и повышает их мотивацию достижения успеха в учебной деятельности. Организация инновационного обучения студентов предполагает, что преподаватели должны уметь не просто стремиться к обогащению своего профессионального опыта, но и уметь воспринимать и внедрять нововведения, развивать способности создавать новый опыт.

Рассматриваемая проблема готовности преподавателей к инновационным преобразованиям в учебно-профессиональной деятельности становится особенно актуальной в современных социально-экономических условиях. Образование как социальная система, должно гибко адаптироваться к изменениям социальной среды и, как следствие, меняться и развиваться. От готовности преподавателей принять и реализовать инновации во многом зависит качество предоставляемых образовательных услуг и, как следствие, результат образования.

Понятие «готовность» определяется, как согласие сделать что-нибудь [14].

По определению В. Даля «готовность» - это состояние и свойство готового, то есть сделавшего все необходимые приготовления, приготовившегося к чему либо [6].

Готовность человека к эффективной деятельности рассматривается в теории и практике образования с различных точек зрения: как условие успешного выполнения деятельности, как избирательная активность, настраивающая личность на будущую деятельность и представляющая концентрацию или мгновенную мобилизацию сил личности, направленную в нужный момент на осуществление определенных действий, как отношение личности к себе (как активному субъекту образовательного процесса), как комплекс способностей, включающих в структуру различные свойства и качества личности (Б.Г. Ананьев, А.Д. Ганюшкин, М.И. Дьяченко, В.Н. Мясищев, К.К. Платонов, Рубинштейн С.Л.).

В научной литературе обозначились два подхода к изучению готовности к деятельности:

- функциональный (М.И. Дьяченко, Л.А. Кандыбович, В.А. Сластенин), при котором готовность рассматривается как комплекс интегрированных, разнородных свойств, различающихся по их месту и функциям в регуляции деятельности; 
- $\quad$ личностный (А.В. Запорожец, В.С. Ильин, Б.Ф. Ломов), при котором готовность определяется как свойство личности, как свойство специальных знаний, умений и навыков, обуславливающих способность выполнять определенную деятельность на достаточно высоком уровне [14].

Научно-теоретические аспекты и ведущие тенденции в развитии инновационных процессов, а также проведенный анализ интегративных качеств, составляющих сущностные черты личности инновационного типа, позволяет рассматривать готовность преподавателей к инновационным преобразованиям в учебно-профессиональной деятельности в качестве необходимой составляющей личностно-профессионального развития, обеспечивающего формирование новых нравственно-гуманистических позиций, качеств, непрерывность роста профессиональной образованности.

Мы определяем следующие компоненты готовности преподавателей к инновационным преобразованиям: мотивационно-ценностные установки, профессиональную компетентность, личностную готовность, технологическую готовность.

Содержанием мотивационно-ценнностных установок являются:

• осознание, понимание фундаментальных ценностей человечества, цивилизаций и культур мира;

- осознание себя как личности и профессионала;

- осознание новых профессиональных целей;

- осознание значимости собственной профессиональной деятельности, нацеленность на результат;

- $\quad$ наличие профессиональной позиции;

- $\quad$ стремление к саморазвитию и профессиональным достижениям;

- ориентация на творческую профессиональную деятельность и качество;

- позитивный настрой на преобразовательную профессиональную деятельность.

Профессиональная компетентность, как компонент готовности преподавателей к инновационным преобразованиям включает развитие профессиональных способностей и профессиональное мастерство:

- профессиональные способности:

- исследовательские (аналитические, познавательные);

- проектировочные (целеполагание, планирование, моделирование и конструирование опережающего, проблемного, системного содержания обучения и образовательного процесса);

- $\quad$ организационные (пунктуальность, работоспособность, дисциплинированность);

- $\quad$ коммуникативные (построение уважительных, доброжелательных, объективно справедливых отношений);

- $\quad$ рефлексивные (осознание себя и ожиданий обучающихся: что изменилось, какой успех получен, открытие новых достижений, альтернатив).

- $\quad$ профессиональное мастерство:

- $\quad$ обогащение системы профессионально-педагогических и специальных знаний и умений; 
- $\quad$ умение осуществлять надежные и точные прогнозы, принимать ответственные решения, в том числе в экстремальных и нестандартных ситуациях;

- ориентация на новые знания, стремление расширить кругозор;

- $\quad$ умение использовать знания в практических целях с высокой эффективностью;

- понимание обязанностей, целей, задач, определение наиболее эффективных способов выполнения профессиональной деятельности;

- $\quad$ освоение новых алгоритмов и способов решения профессиональных задач и использование новых технических средств деятельности;

- $\quad$ способность предвидеть, предвосхищать, быстро реагировать на изменяющиеся условия.

К личностной готовности относятся:

- $\quad$ личностные качества: ответственность за результаты своего труда, системность мышления, самопознание, стремление к творческой самореализации, стрессоустойчивость, адаптивность, самостоятельность, инициативность, уверенность в успехе, нравственно-волевая саморегуляция, эрудированность, тактичность, владение собой, выдержанность, др.

- $\quad$ интегральные психические свойства личности: внимание, память, воображение, др.

- личностная, общая и профессиональная культура:

- культура преподавания (логичность, четкость, выразительность, правильность, точность речи);

- профессионально-терминологическая грамотность (педагогическая, техническая, экономическая и др.);

- стиль поведения и взаимодействия в образовательном процессе.

Технологическая готовность включает:

- $\quad$ умение организовывать и специально создавать развивающую образовательную среду;

- построение образовательного процесса на основе современных технологий обучения: модульное, проблемное, поисковое, проектное и др.;

- владение методами реализации инноваций, осуществление нововведений с максимальной эффективностью.

Критериями готовности преподавателей к инновационной образовательной деятельности могут служить:

- $\quad$ способность видеть мир целостно, в единстве его многообразия;

- способность принять изменения, происходящие в системе высшей школы и активно участвовать в их реализации, обеспечивая преобразование образовательной среды (процесса) и содержания из исходного состояния в требуемое устойчивым развитием;

- способность соответствовать изменениям, вызванными успехами научнотехнического прогресса; 
- способность удовлетворять потребность обучающихся в качественном образовании сегодня для будущего.

Быть готовым к инновационной деятельности - значит, обладать качествами и способностями, обеспечивающими организацию образовательного процесса в режиме развития. Именно развитие обеспечивает общность и единство педагогического процесса, оптимальные условия организации педагогического пространства и взаимодействия преподавателя с обучающимися, способствует системному освоению студентами содержания предметной области и непрерывному овладению культурой через освоение совокупности необходимых предметных знаний, способностей в конкретной области, позволяющих органично включать их в свою жизнедеятельность.

\section{ЛИТЕРАТУРА}

1. Ананьев Б.Г. Избранные психологические труды: В 2т. / Б.Г. Ананьев - Т.1 - М.: Педагогика, 1980. - 232 с.

2. Аношкина В.Л., Резванов С.В. Образование. Инновация. Будущее. (Методологические и социокультурные проблемы). - Ростов-на-Дону: Изд-во РО ИПК и ПРО, 2001. - 176 с.

3. Герасимов Г.И., Илюхина Л.В. Инновации в образовании: сущность и социальные механизмы. - Ростов н/д: НМД «Логос», 1999. - 136 с.

4. Гурье Л.И. Интегративные основы инновационного образовательного процесса в высшей профессиональной школе: монография / Л.И. Гурье, А.А. Кирсанов, В.В. Кондратьев, И.Э. Ярмакеев; под редакцией В.В.Кондратьева. - М.: ВИНИТИ, 2006. - 288 с.

5. Даль В. Толковый словарь живого великорусского языка. - М.: Русский язык, 1981. Т. 2. -779 c.

6. Дудкин Ф.Ю. Человек в системе российского менеджмента. Ростов-на-Дону, 1997.

7. Дьяченко М.И. Краткий психологический справочник: Личность, образование, самообразование, профессия / М.И. Дьяченко, Л.А. Кандыбович. - Мн.: Хэлтон, 1998. - 339 c.

8. Карпова Ю.А. Инновации, интеллект, образование. М., 1998.

9. Crozier M. L'enterprise a L'ecounte. Apprendre le manaqement postindustriale. P.1991

10. Лапин Н.И. Актуальные проблемы исследования нововведений. / В сб.: Социальные факторы нововведений в организационных системах. - М., 1980.

11. Лапин Н.И., Пригожий А.И., Сазонов Б.В., Толстой В.С. Нововведения в организациях. В сб.: Структура инновационного процесса. - М., 1981.

12. Ломов Б.Ф. Системность в психологии: Избранные психологические труды / Б.Ф. Ломов. М.: МПСИ; Воронеж: НПО «МОДЭК», 2003. - 424 с.

13. Ожегов С.И. Словарь русского языка. - М.: Русский язык, 1982. - 816 с.

14. Педагогика профессионального образования: учеб. пособие для студ. высш. пед. учеб. заведений / Е.П. Белозерцев, А.Д. Гонеев, А.Г. Пашков и др. Под ред. В.А. Сластенина. - М.: Издательский центр «Академия», 2004. - 368 с. 
15. Поляков С.Д. В поисках педагогической инновации. - М.: Дрофа, 2003.

16. Сластенин В.А. Готовность педагога к инновационной деятельности /

Сластенин, Л.С. Подымова // Педагогическая наука и образование. - 2006. - № 1. - C. 32-37.

17. Современные факторы повышения качества профессионального образования: материалы XXVIII преподавательской научно-практической конференции. Том 4. Секции общей педагогики и педагогики высшей школы / Мин-во образования и науки РФ, Оренбург. гос. пед. ун-т. - Оренбург: Изд-во ОГПУ, 2007. - 308 с.

18. Технологии управления инновационной деятельностью: Учебное пособие / Китова Г.Н., Китов А.Г, Зотова В.А. - Н.Новгород: НГПУ им.К.Минина, 2012. 384 c.

19. Томилин О.Б. Компетенции академического и административного персонала университета и инновационная деятельность / О. Б. Томилин, П. Н. Кочугаев, Л.А. Сухарев, Н. Н. Массерова // Университетское управление. - 2007. - № 1. C. $53-61$.

Рецензент: Папуткова Галина Александровна, проректор по учебно-методической деятельности, доктор педагогических наук, профессор, ФГБОУ ВПО «Нижегородский государственный педагогический университет им. К.Минина». 
Bicheva Irina Borisovna

Nizhniy Novgorod State Pedagogical University

Russia, Nizhny Novgorod

E-Mail: irinabicheva@bk.ru

Kitov Anatoly Grigor'evich

Nizhniy Novgorod State Pedagogical University

Russia, Nizhny Novgorod

E-Mail: anatolykitov@yndex.ru

\title{
About the readiness of teachers to innovative transformations in teaching and professional activities
}

\begin{abstract}
Innovations have a special place in the education system as a social institution and the willingness of teachers to innovative transformations is an important condition for the modernization of education. The willingness of teachers to adopt and implement innovations depends largely on the quality of educational services and, as a consequence, the result of education. However, the scientific literature is not enough research prove the necessity of formation of readiness of teachers to innovative changes in teaching and professional activities.

In article theoretical aspects and leading trends in the development of innovative processes in education, highlighting the innovative principles of the educational process, are considered integrative qualities, which form the essential personality traits of innovative type.

The willingness of people to effective action is considered in the theory and practice of education as a condition for the successful implementation of the activity as selective activity as the ratio of the individual to himself (as the active subject of the educational process), as a complex of abilities, including the structure of the different properties and qualities.

The publication says that to be ready to innovate means to possess the qualities and abilities, provide for the organization of the educational process in the development mode. The willingness of teachers to innovative reforms in the educational-professional activity is considered as a necessary component of personal and professional development, ensuring the formation of a new moralhumanistic attitudes, qualities, continuous growth of professional education.

The article describes the components of readiness of teachers to innovative reforms, including motivational and values, professional competence, personal and technological readiness, as well as criteria of readiness of teachers to innovative educational activities.

Keywords: innovation; innovation process; innovative principles of the educational process; innovative personality type; readiness; readiness for innovative activity; criteria; the components of readiness for innovative changes.
\end{abstract}




\section{REFERENCES}

1. Anan'ev B.G. Izbrannye psikhologicheskie trudy: V 2t. / B.G. Anan'ev - T.1 - M.: Pedagogika, 1980. - 232 s.

2. Anoshkina V.L., Rezvanov S.V. Obrazovanie. Innovatsiya. Budushchee. (Metodologicheskie i sotsiokul'turnye problemy). - Rostov-na-Donu: Izd-vo RO IPK i PRO, 2001. - $176 \mathrm{~s}$.

3. Gerasimov G.I., Ilyukhina L.V. Innovatsii v obrazovanii: sushchnost' i sotsial'nye mekhanizmy. - Rostov n/d: NMD «Logos», 1999. - 136 s.

4. Gur'e L.I. Integrativnye osnovy innovatsionnogo obrazovatel'nogo protsessa v vysshey professional'noy shkole: monografiya / L.I. Gur'e, A.A. Kirsanov, V.V. Kondrat'ev, I.E. Yarmakeev; pod redaktsiey V.V.Kondrat'eva. - M.: VINITI, 2006. - $288 \mathrm{~s}$.

5. Dal' V. Tolkovyy slovar' zhivogo velikorusskogo yazyka. - M.: Russkiy yazyk, 1981. T. 2. $-779 \mathrm{~s}$.

6. Dudkin F.Yu. Chelovek v sisteme rossiyskogo menedzhmenta. Rostov-na-Donu, 1997.

7. D'yachenko M.I. Kratkiy psikhologicheskiy spravochnik: Lichnost', obrazovanie, samoobrazovanie, professiya / M.I. D'yachenko, L.A. Kandybovich. - Mn.: Khelton, 1998. - 339 s.

8. Karpova Yu.A. Innovatsii, intellekt, obrazovanie. M., 1998.

9. Crozier M. L'enterprise a L'ecounte. Apprendre le manaqement postindustriale. P.1991

10. Lapin N.I. Aktual'nye problemy issledovaniya novovvedeniy. / V sb.: Sotsial'nye faktory novovvedeniy v organizatsionnykh sistemakh. - M., 1980.

11. Lapin N.I., Prigozhiy A.I., Sazonov B.V., Tolstoy B.C. Novovvedeniya v organizatsiyakh. V sb.: Struktura innovatsionnogo protsessa. - M., 1981.

12. Lomov B.F. Sistemnost' v psikhologii: Izbrannye psikhologicheskie trudy / B.F. Lomov. M.: MPSI; Voronezh: NPO «MODEK», 2003. - 424 s.

13. Ozhegov S.I. Slovar' russkogo yazyka. - M.: Russkiy yazyk, 1982. - 816 s.

14. Pedagogika professional'nogo obrazovaniya: ucheb. posobie dlya stud. vyssh. ped. ucheb. zavedeniy / E.P. Belozertsev, A.D. Goneev, A.G. Pashkov i dr. Pod red. V.A. Slastenina. - M.: Izdatel'skiy tsentr «Akademiya», 2004. - 368 s.

15. Polyakov S.D. V poiskakh pedagogicheskoy innovatsii. - M.: Drofa, 2003.

16. Slastenin V.A. Gotovnost' pedagoga k innovatsionnoy deyatel'nosti / V.A. Slastenin, L.S. Podymova // Pedagogicheskaya nauka i obrazovanie. - 2006. - № 1. S. 32-37.

17. Sovremennye faktory povysheniya kachestva professional'nogo obrazovaniya: materialy XXVIII prepodavatel'skoy nauchno-prakticheskoy konferentsii. Tom 4. Sektsii obshchey pedagogiki i pedagogiki vysshey shkoly / Min-vo obrazovaniya i nauki RF, Orenburg. gos. ped. un-t. - Orenburg: Izd-vo OGPU, 2007. - 308 s.

18. Tekhnologii upravleniya innovatsionnoy deyatel'nost'yu: Uchebnoe posobie / Kitova G.N., Kitov A.G, Zotova V.A. — N.Novgorod: NGPU im.K.Minina, 2012. - 384 s.

19. Tomilin O.B. Kompetentsii akademicheskogo i administrativnogo personala universiteta i innovatsionnaya deyatel'nost' / O. B. Tomilin, P. N. Kochugaev, L.A. Sukharev, N. N. Masserova // Universitetskoe upravlenie. - 2007. - № 1. - S. 53 - 61. 